\title{
Impact of Electron Radiation Dose to the Performance of Half- Wave Rectifier and Converter Circuits with Silicon Carbide Schottky Diode
}

\author{
N.F. Hasbullah ${ }^{1}$, Nafiz 'Irfan Shuhaimi' ${ }^{1}$ Yusof Abdullah ${ }^{2}$,M.A.Khairi ${ }^{1}$ \\ ${ }^{1,3}$ Department of Electrical and Computer Engineering, Kulliyyah of Engineering, International Islamic University \\ Malaysia (IIUM), Malaysia \\ ${ }^{2}$ Industrial Technology Division, Malaysia Nuclear Agency, Bangi. Malaysia
}

\begin{tabular}{l} 
Article Info \\
\hline Article history: \\
Received May 21, 2020 \\
Revised May 21, 2020 \\
Accepted Jun 11, 2020 \\
\hline Keywords: \\
4H-SiC Schottky Diode \\
Electron irradiation \\
Half-wave rectifier \\
Bulk Converter \\
Boost Converter
\end{tabular}

\begin{abstract}
Half-wave rectifier; buck; and boost converter with electron-irradiated, highvoltage silicon carbide Schottky power diodes from CREE, Inc., performance was studied and presented in this paper subjected to electron radiation. The diodes were irradiated by high-energy ( $3 \mathrm{MeV}$ ) electrons with doses ranging from 1 to $5 \mathrm{MGy}$. The performance of the circuits in term of the output voltage were measured before and after the diodes being irradiated. It was observed, at $4 \mathrm{MGy}$, the half-wave rectifier output voltage degrades by 6.2 times as compared to before irradiation. Meanwhile, the output voltage of the buck converter degrades by 1.7 times; and for boost converter, the degradation of the output voltage is approximately 4.6 times for $4 \mathrm{MGy}$ radiation. These degradations are believed to be due to the increase in the series resistance of the Schottky diodes which is caused by the defects introduced inside the semiconductor during the irradiation and also the increase of turn-on voltage of the diodes after being irradiated.
\end{abstract}

Copyright (C) 2020 Institute of Advanced Engineering and Science. All rights reserved.

Corresponding Author:

Nurul Fadzlin Hasbullah,

Department of Electrical and Computer Engineering,

International Islamic University Malaysia,

Jalan Gombak, 53100, Gombak, Kuala Lumpur, Malaysia.

Email:nfadzlinh@iium.edu.my

\section{INTRODUCTION}

Silicon carbide is being considered as a potential alternative to silicon for the manufacture of dosimeters, spectrometers and charge-particle detectors in high energy physics experiment due to its high radiation hardness [1]-[10]. The outstanding physical properties of silicon carbide has made it a material of choice to be used in optoelectronics and electronics devices working in an extreme environment [11]-[14]. Schottky diodes have attracted great interest in satellite and power converter applications due to its fast switching speed, lower reverse breakdown voltage and low voltage loss [15]-[17]. Silicon carbide (SiC) Schottky diodes have been shown to be the most suitable candidate for replacing the conventional diodes e.g. silicon ( $\mathrm{Si}$ ) diodes due to its high radiation hardness in an extreme environment environments [11], [18][20]. Radiation hardness is usually associate with the stability of parameters of a semiconductor or a semiconductor device under irradiation. The higher the irradiation dose required for the parameters to start deteriorating, the better the radiation hardness of the semiconductor [21]. In this paper, the results and analysis on the changes of the overall performance of half-wave rectifier; buck; and boost converter containing SiC Schottky diodes which were subjected to electron radiation are presented. The focus of this paper is the performance of the three circuits instead of the performance of the schotkky diode. A half-wave rectifier is a circuit that converts full wave input of alternating current $(\mathrm{AC})$ signal into half wave direct current (DC) signal; while a buck converter is a switch mode DC to DC electronic converter in which the output voltage will be transformed to level less than the input voltage; and a boost converter is a switch mode DC to DC converter in which the output voltage is greater than the input voltage. All of the circuits are 
important components in satellites [22]. The measurements were done with different switching frequencies and different duty cycles. The responses of the circuits before and after the SiC Schottky diodes being irradiated are discussed in detail.

\section{EXPERIMENTAL DETAILS}

Commercial SiC Schottky diodes from CREE, Inc., with a reverse peak voltage of $600 \mathrm{~V}$ was chosen for investigation. Three types of circuit i.e. half-wave rectifier, buck and boost converter were tested; and a total of 15 diodes were used to check for repeatability. Note that, the irradiation procedure was only done upon the diodes. The SiC Schottky diodes with nominally similar pre-irradiation electrical characteristics were irradiated at room temperature by $3 \mathrm{MeV}$ electrons at doses of 1, 2, 3, 4, and 5 MGy using Electron Beam Machine with flux rate of $50 \mathrm{kGy} /$ pass at Malaysia Nuclear Agency. A total of three samples was prepared for each dose. The assessment on the circuit electrical performance were done on the half-wave rectifier, buck converter and boost converter circuits as shown in Fig. 1(a), 1(b) and 1(c) respectively. The half-wave rectifier circuit is made up of an AC power generator and a 100 ohms resistor. The buck converter circuit consists of a $1 \mathrm{mH}$ inductor, $10 \mathrm{ohms}$ of a load resistor, a $330 \mu \mathrm{F}$ of capacitor and a power MOSFET. Lastly, the boost converter is made up of a $1 \mathrm{mH}$ inductor, a $33 \mu \mathrm{F}$ capacitor, a $100 \mathrm{ohms}$ resistor and a power MOSFET. The overall performance of the circuits was tested before and after irradiation of the SiC Schottky diodes.

(a)

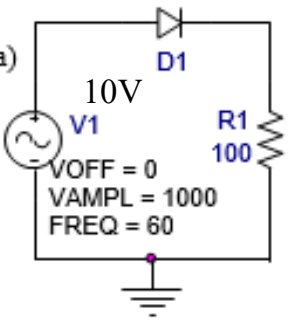

(b)

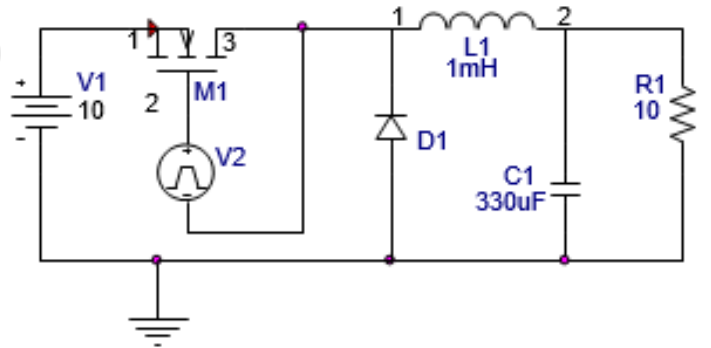

(C)

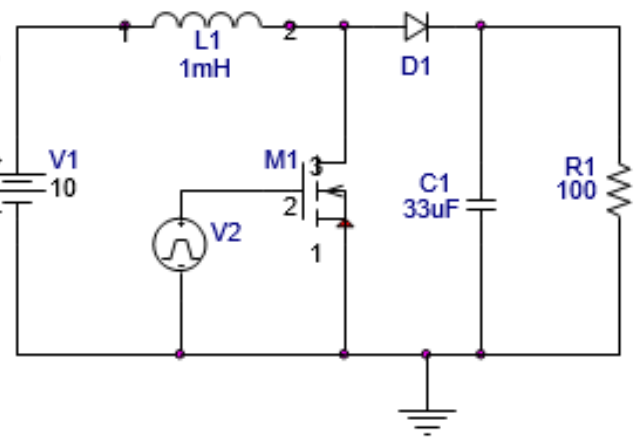

Figure. 1. Schematic of (a) half-wave rectifier, (b) buck converter and (c) boost converter circuits.

\section{RESULTS AND DISCUSSION}

\subsection{Half-Wave Rectifier Circuit Characterization}

The peak output voltage of the half-wave rectifier circuit in Fig. 1(a) was investigated using CREE Schottky diodes before and after irradiation. The peak output voltage of the circuit was measured, and Fig. 2 shows the mean of the peak voltages from the 3 different devices irradiated in every dose. From the figure, it can be seen that after irradiation, the average voltage across the load resistor decreases sharply and remains constant up to $3 \mathrm{MGy}$ before it sharply decreases again when irradiated with $4 \mathrm{MGy}$ dose. This degradation can be explained by the increase in series resistance observed after irradiation which is common in $\mathrm{SiC}$ Schottky diode as reported in [22]-[25]. The higher the series resistance, the more voltage drop across the resistance in the circuit, thus reducing the overall output peak voltage of the circuit. The result of the series resistance for these devices were submitted to another journal paper. 


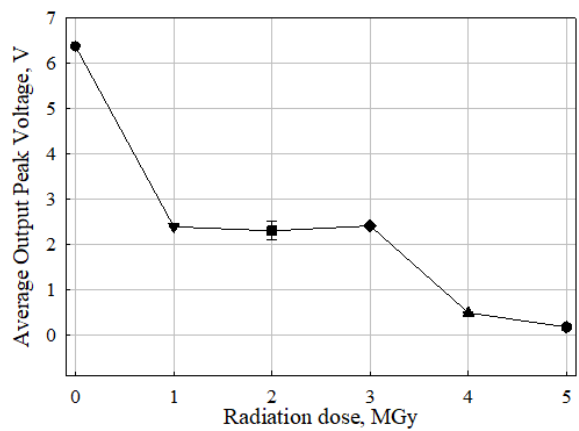

Figure 2. Average peak voltage across load resistor of half-wave circuit containing CREE SiC Schottky diode irradiated to 1, 2, 3, 4 and $5 \mathrm{MGy}$. Error bars indicate the standard deviation of the average voltage

\subsection{Buck Converter Circuit Characterization}

Buck converter (Fig. 1(b)) with 10V DC input was also tested using the CREE SiC Schottky diodes before and after electron irradiation. The circuit performance was investigated by two switching frequencies i.e. $10 \mathrm{kHz}$ to $100 \mathrm{kHz}$ as in Ref. 5. Fig. 3(a) and (b) shows the plot of the average output voltage across the load resistor as a function of radiation dose at $10 \mathrm{kHz}$ and $100 \mathrm{kHz}$ switching frequency tested with $25 \%$ to $75 \%$ duty cycles. It can be seen in Fig. 3 that, the output voltage of the circuit for both switching frequencies increases with increasing duty cycle for all dose levels.
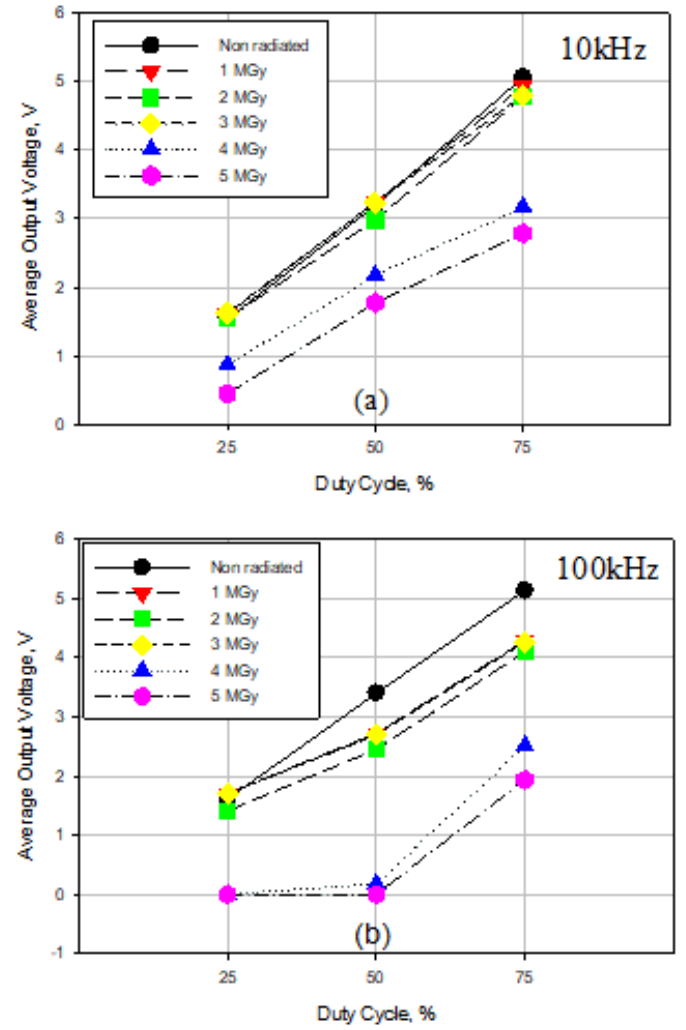

Figure. 3. Average output voltage across load resistor of buck converter circuit containing CREE SiC Schottky diode as a function of irradiation dose with (a) $10 \mathrm{kHz}$ and (b) $100 \mathrm{kHz}$ switching frequency tested with different duty cycles.

A plot of average output voltage with respect to doses across the load resistor as a function of duty cycle at $10 \mathrm{kHz}$ and $100 \mathrm{kHz}$ are shown in Fig. 4(a) and (b) respectively. Generally, the DC output voltage across the load resistor decreases with increasing dose especially at 4 MGy - the rate of decrement is significant i.e. 1.7 times is more affected for $100 \mathrm{kHz}$ as compared to our $100 \mathrm{kHz}$ Hence, higher frequencies is more vulnerable with radiation damage. This implies that the buck converter performance has degraded with increasing dose of radiation. Similar to the half-wave rectifier, series resistance plays an important role in the voltage drop across the diode causing a reduction in the average output voltages. Moreover, the output 
voltage is more affected for $100 \mathrm{kHz}$ as compared to $10 \mathrm{kHz}$. Hence, higher frequencies are more vulnerable with radiation damage. The increase of the output voltage is believed to be due to the increases in turn-on voltage of the diodes and also the increase of the internal resistance within the Schottky diode with the increasing irradiation dose. Meanwhile, Fig. 5 shows the turn-on voltage increment of the SiC diode from $0.82 \mathrm{~V}$ to $0.84 \mathrm{~V}$ before and after irradiation. This supports the effect of the increase of the output voltage with increased radiation dose. The detailed analysis of the increase of the internal resistance of the SiC diode is published in another paper.
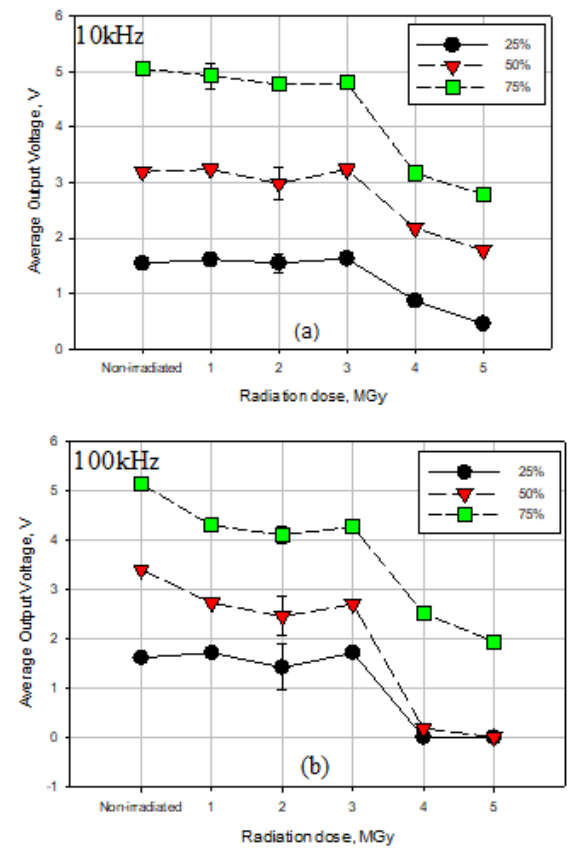

Figure. 4. Average output voltage across load resistor of buck converter circuit containing CREE SiC Schottky diode irradiated to 1,2, 3, 4 and $5 \mathrm{MGy}$ as a function of duty cycle with (a) $10 \mathrm{kHz}$ and (b) 100 $\mathrm{kHz}$ switching frequency.

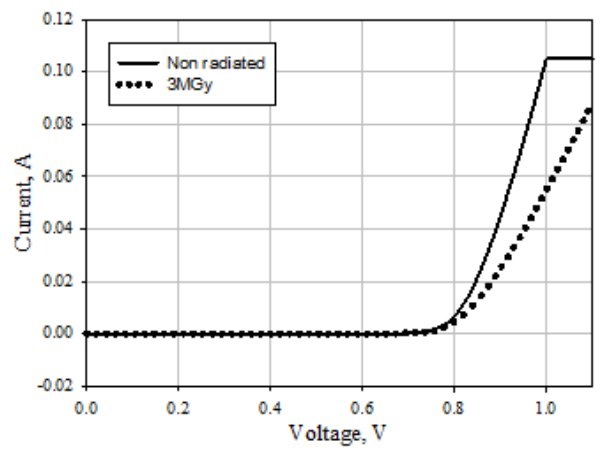

Figure. 5. Forward bias I-V characterization of CREE Schottky diode before and after irradiation

\subsection{Boost Converter Circuit Characterization}

A boost converter circuit with $5 \mathrm{~V}$ DC input as in Fig. 1(c) was also tested with the same parameters of the buck converter earlier. The average output voltage across the load resistor with respect to irradiation doses at $10 \mathrm{kHz}$ to $100 \mathrm{kHz}$ switching frequency, tested with different duty cycles were plotted and shown in Fig. 6(a) and (b) respectively. It was observed that, the circuit experiences similar trend to the buck converter where the output voltage increases with increasing duty cycle [25]-[28] However, the circuit can only achieve a maximum output voltage of $5.97 \mathrm{~V}$ before the power is loss in term of heat dissipation, where significant reduction of the output voltage at $75 \%$ duty cycle for all frequencies. 

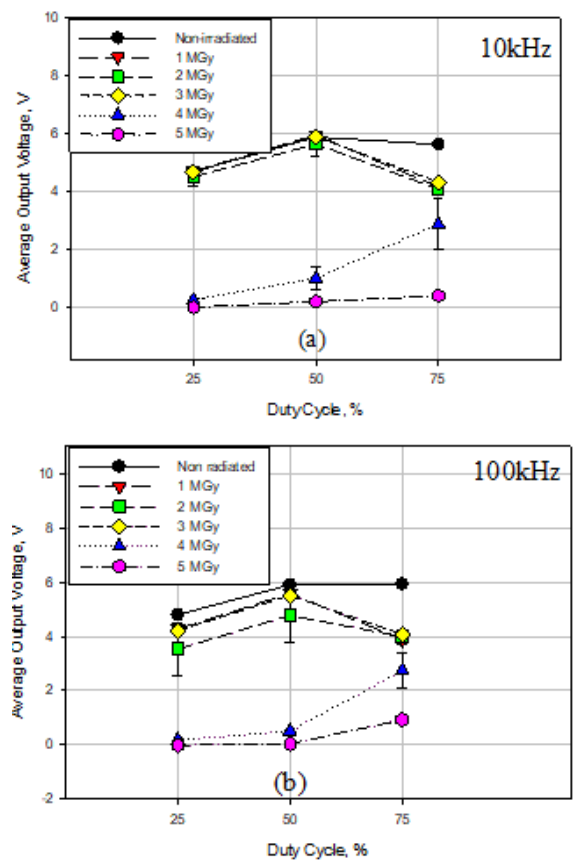

Figure. 6. Average output voltage across load resistor of boost converter circuit containing CREE SiC Schottky diode as a function of irradiation dose with (a) $10 \mathrm{kHz}$ and (b) $100 \mathrm{kHz}$ switching frequency tested with different duty cycles

Meanwhile, the average output voltage in term of dose as a function of duty cycle at $10 \mathrm{kHz}$ and $100 \mathrm{kHz}$ are plotted as in Fig. 7. The trend is also similar to the buck converter i.e. the average output voltage decreases with increasing dose especially at $4 \mathrm{MGy}$, the rate of decrement is 4.6 times. The degradation is suggested to be due to the increase in the series resistance of the Schottky diodes after irradiation which results in greater voltage drop across the diode [29]. Similar to the buck converter, the magnitude of the turnon voltage of the Schottky diode is important in explaining the voltage differences.
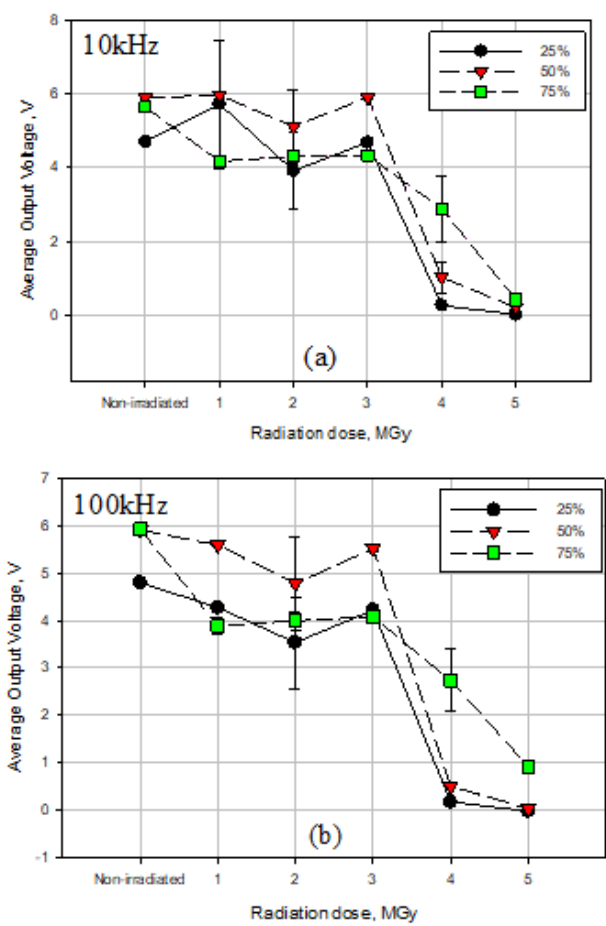

Figure. 7. Average output voltage across load resistor of buck converter circuit containing CREE SiC Schottky diode irradiated with 1, 2, 3, 4 and 5 MGy as a function of duty cycle with (a) $10 \mathrm{kHz}$ and (b) 100 $\mathrm{kHz}$ switching frequency 


\section{CONCLUSION}

The radiation responses of the $\mathrm{SiC}$ Schottky diode and its corresponding effects on the half-wave rectifier, buck converter, and boost converter output voltage were investigated. In conclusion, all circuits studied using CREE SiC Schottky diodes, show degradation in their performances after electron irradiation of 1, 2, 3, 4 and $5 \mathrm{MGy}$. The average output voltage of the half-wave rectifier degrades by 6.2 times at 4 MGy; whereas, the buck converter shows degradation of 1.7 times at 4 MGy; and for boost converter, the degradation is about 4.6 times at $4 \mathrm{MGy}$. The degradation is accounted to the increases in the series resistance and forward voltage of the Schottky diodes after irradiation. After irradiation effect shows that, high switching frequency of the converter circuits account for higher performance degradation which is caused by the increases of the turn-on voltage of the Schottky diode. Overall, the circuits may operate but with degraded performance, thus, precautions need to be taken so that the decrease of the overall circuit can be tolerated when subjected to electron radiation.

\section{ACKNOWLEDGEMENTS}

This work was supported by Ministry of Higher Education, Malaysia under Research Grant FRGS 15-244-0485 and RIGS16-338-0502.

\section{REFERENCES}

[1] F. Moscatelli et al., "Radiation hardness after very high neutron irradiation of minimum ionizing particle detectors based on 4H-SJC p +n junctions," IEEE Trans. Nucl. Sci., vol. 53, no. 3, pp. 1557-1563, 2006, doi: 10.1109/TNS.2006.872202.

[2] F. H. Ruddy, A. R. Dulloo, J. G. Seidel, S. Seshadri, and L. B. Rowland, "Development of a silicon carbide radiation detector," IEEE Trans. Nucl. Sci., vol. 45, no. 3, pp. 536-541, 1998, doi: 10.1109/23.682444.

[3] F. Nava, P. Vanni, C. Lanzieri, and C. Canali, "Erratum to 'Epitaxial silicon carbide charge particle detectors' [Nucl. Instr. and Meth. A 437 (1999) 354-358]," Nucl. Instruments Methods Phys. Res. Sect. A Accel. Spectrometers, Detect. Assoc. Equip., vol. 446, no. 3, p. 600, 2000, doi: 10.1016/s0168-9002(00)00162-5.

[4] M. Bruzzi, F. Nava, S. Russo, S. Sciortino, and P. Vanni, "Characterisation of silicon carbide detectors response to electron and photon irradiation," Diam. Relat. Mater., vol. 10, pp. 657-661, Mar. 2001, doi: 10.1016/S09259635(00)00380-0.

[5] F. Nava et al., "Charged Particle Detection Properties of Epitaxial 4H-SiC Schottky Diodes," Mater. Sci. Forum - MATER SCI FORUM, vol. 353-356, pp. 757-762, Jan. 2001, doi: 10.4028/www.scientific.net/MSF.353356.757.

[6] G. Bertuccio, R. Casiraghi, and F. Nava, "Epitaxial silicon carbide for X-ray detection," IEEE Trans. Nucl. Sci., vol. 48, no. 2, pp. 232-233, 2001, doi: 10.1109/23.915369.

[7] F. Nava et al., "Radiation tolerance of epitaxial silicon carbide detectors for electrons, protons and gamma-rays," Nucl. Instruments Methods Phys. Res. Sect. A Accel. Spectrometers, Detect. Assoc. Equip., vol. 505, pp. 645655, Jun. 2003, doi: 10.1016/S0168-9002(02)01558-9.

[8] F. Nava et al., "Minimum Ionizing and Alpha Particles Detectors Based on Epitaxial Semiconductor Silicon Carbide," Nucl. Sci. IEEE Trans., vol. 51, pp. 238-244, Mar. 2004, doi: 10.1109/TNS.2004.825095.

[9] M. Bruzzi, S. Lagomarsino, F. Nava, and S. Sciortino, "Characterisation of epitaxial SiC Schottky barriers as particle detectors," Diam. Relat. Mater., vol. 12, pp. 1205-1208, Mar. 2003, doi: 10.1016/S09259635(02)00350-3.

[10] A. Bruzzi, F. Hartjes, S. Lagomarsino, F. Nava, S. Sciortino, and P. Varnni, "Recent results on particle detection with epitaxial SiC Schottky diodes," in 2002 IEEE Nuclear Science Symposium Conference Record, 2002, vol. 1, pp. 14-17 vol.1, doi: 10.1109/NSSMIC.2002.1239258.

[11] K. K. Lee, T. Ohshima, A. Saint, T. Kamiya, D. N. Jamieson, and H. Itoh, "A comparative study of the radiation hardness of silicon carbide using light ions," Nucl. Instruments Methods Phys. Res. Sect. B Beam Interact. with Mater. Atoms, vol. 210, pp. 489-494, 2003, doi: 10.1016/S0168-583X(03)01096-6.

[12] W. Wesch, “cm . ," vol. 116, pp. 305-321, 1996.

[13] P. J. Sellin and J. Vaitkus, "New materials for radiation hard semiconductor dectectors," Nucl. Inst. Methods Phys. Res. A, vol. 557, no. 2, pp. 479-489, 2006, doi: 10.1016/j.nima.2005.10.128.

[14] A. A. Lebedev, Radiation Effects in Silicon Carbide. Materials Research Forum LLC, 2017.

[15] H. Hsu, "Understanding semiconductor devices [Book Review]," IEEE Circuits Devices Mag., vol. 17, no. 5, p. 44, 2001, doi: 10.1109/MCD.2001.960691.

[16] M. H. Rashid, Power Electronics Handbook. Elsevier Science, 2011.

[17] A. A. Nawawi, S. M. Sultan, S. F. A. Rahmah, P. I. Khalid, and S. H. Pu, "Reverse biased nanocrystalline graphite (NCG)/p-Si schottky junction for methane gas sensor," Indones. J. Electr. Eng. Comput. Sci., vol. 15, no. 3, p. 1217, 2019, doi: 10.11591/ijeecs.v15.i3.pp1217-1222.

[18] P. Godignon et al., "SiC Schottky Diodes for Harsh Environment Space Applications," IEEE Trans. Ind. Electron., vol. 58, no. 7, pp. 2582-2590, 2011, doi: 10.1109/TIE.2010.2080252.

[19] F. Nava, A. Castaldini, A. Cavallini, P. Errani, and V. Cindro, "Radiation Detection Properties of 4H-SiC Schottky Diodes Irradiated Up to $<$ tex $>\$ 10^{\wedge} 16 \$</$ tex $>$ n $/ \mathrm{cm}<$ tex $>\$ \wedge 2 \$</$ tex $>$ by $1 \mathrm{MeV}$ Neutrons," IEEE Trans. Nucl. Sci., vol. 53, no. 5-2, pp. 2977-2982, 2006, doi: 10.1109/TNS.2006.882777. 
[20] N. Iwamoto et al., "Defect-induced performance degradation of 4H-SiC Schottky barrier diode particle detectors," J. Appl. Phys., vol. 113, no. 14, 2013, doi: 10.1063/1.4801797.

[21] A. A. Lebedev et al., "Radiation hardness of wide-gap semiconductors (using the example of silicon carbide)," Semiconductors, vol. 36, no. 11, pp. 1270-1275, 2002, doi: 10.1134/1.1521229.

[22] S. F. O. Abubakkar, N. F. Zabah, Y. Abdullah, D. A. Fauzi, N. Muridan, and N. F. Hasbullah, "Effects of electron radiation on commercial power MOSFET with buck converter application," Nucl. Sci. Tech., vol. 28, no. 3, pp. 1-5, 2017, doi: 10.1007/s41365-017-0189-8.

[23] S. Ganiyev, N. Muridan, N. F. Hasbullah, and Y. Abdullah, "Electrical simulation of Ni/4H-SiC Schottky diodes before and after low energy electron radiation," in 2015 IEEE Regional Symposium on Micro and Nanoelectronics (RSM), 2015, pp. 1-4, doi: 10.1109/RSM.2015.7354995.

[24] Y. Abdullah et al., "Effects of Neutron and Electron Irradiation on 4H-SiC Diodes," Mater. Sci. Forum, vol. 840, pp. 281-286, 2016, doi: 10.4028/www.scientific.net/MSF.840.281.

[25] J. A. Kulisek and T. E. Blue, "Neutron and Proton Radiation Damage and Isothermal Annealing of Irradiated SiC Schottky Power Diodes," AIP Conf. Proc., vol. 1103, no. 1, pp. 478-485, Mar. 2009, doi: 10.1063/1.3115555.

[26] T. L. Floyd, Electronic Devices: Conventional Current Version. Prentice Hall, 2012.

[27] D. A. Neamen, Electronic circuit analysis and design. McGraw-Hill, 2001.

[28] B. Khorsandi, J. Kulisek, T. E. Blue, D. Miller, J. Baeslack, and S. Stone, "Analysis of Displacement Damage Dose and Low Annealing Temperatures on the I-V Characteristics of SiC Schottky Diodes Using ANOVA Method," Nucl. Technol., vol. 172, no. 3, pp. 295-301, Dec. 2010, doi: 10.13182/NT10-A10938.

[29] P. C. Adell and L. Z. Scheick, "Radiation effects in power systems: A review," IEEE Trans. Nucl. Sci., vol. 60, no. 3, pp. 1929-1952, 2013, doi: 10.1109/TNS.2013.2262235. 


\section{BIOGRAPHY OF AUTHORS}
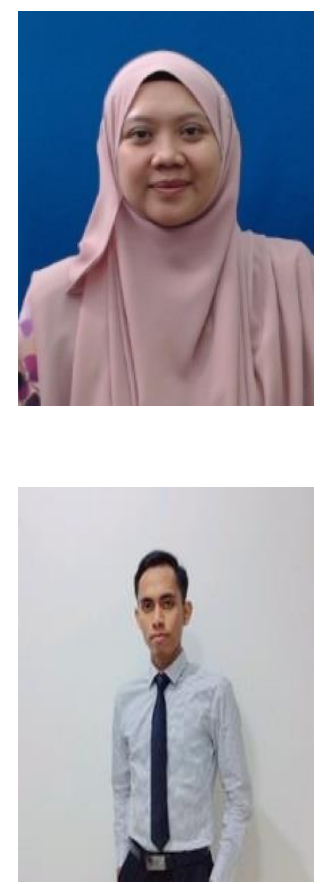

Nafiz 'Irfan Shuhaimi' ${ }^{1}$ received the B.Eng. degree in Manufacturing Engineering in 2019 from International Islamic University Malaysia, Malaysia. characterization of radiation hard electronics and semiconductor materials.
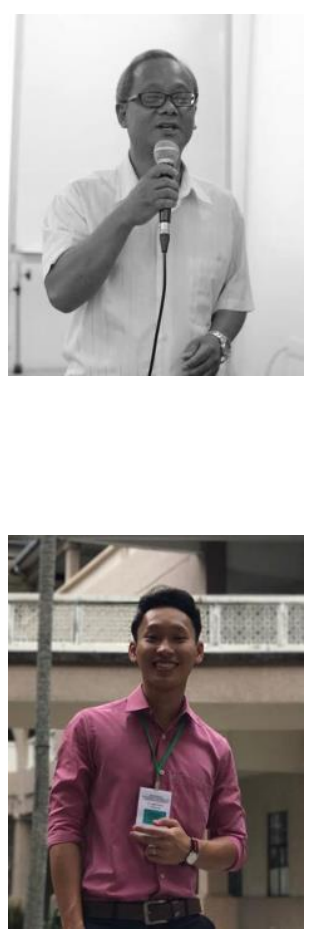

Nurul Fadzlin Hasbullah (N.F. Hasbullah) received the Ph.D. in Electronics Engineering from the University of Sheffield, Sheffield, U.K. in 2009 and B.Eng. degree in electrical and electronic engineering from Cardiff University, Wales, U.K., in 2001. She was an IC design engineer at Malaysia Microelectronic Solutions in 2001. Since 2010, she has been with the International Islamic University Malaysia, where she is currently an Associates Professor at the Department of Electrical and Computer Engineering. Her current research interest includes

The late Ts. Dr. Yusof Abdullah (1962 - 2019) was a Principal Research Officer of Industrial Technology, Malaysian Nuclear Agency. Dr. Yusof Abdullah received M.Sc. (Eng.) from the University of Sheffield, U.K. in 1997 and Ph.D. degree in 2009 from the National University of Malaysia (UKM). He had 28 years of experience in R\&D fields of radiation damage study, advanced materials, material characterization, and corrosion and coating materials. He has published more than 100 journal and conference papers as a key author and had received multiple research grants and granted awards from societies and institutes

Mohamad Azim Mohd Khairi (M. Azim Khairi) received the B.Eng. degree in Manufacturing Engineering in 2017 and Ms.c (Eng.) in Electronics Engineering in 2019 from International Islamic University Malaysia, Malaysia. He is a growing researcher who currently has several research papers focusing on electrical behaviour of Silicon Carbide Schottky diode, nuclear (space) radiation, semiconductor materials, radiation hard electronics devices, modelling and reliability test 